\title{
Welcome From the Program Committee
}

doi:10.1017/S1431927614013142

Welcome to this Microscopy and Microanalysis meeting, M\&M 2014 in Hartford, Connecticut!

The Microscopy Society of America, the Microanalysis Society, and the International Metallographic Society, and the Canadian Microscopy Society have excelled in bringing the latest and most innovative applications and instrumental developments from investigators in the biological and physical sciences using microscopy and microanalysis techniques. M\&M 2014 features more than 37 symposia covering a broad range of topics, ample educational opportunities in the form of courses/tutorials and pre-meeting events including courses, a congress and a workshop. This year is special as we also welcome the Microscopical Society of Canada and the International Union of Microbeam Analysis Societies (IUMAS) who will hold their IUMAS-6 meeting prior to M\&M 2014.

This year we are honored to welcome two world renowned scientists, Professor Sir. Colin Humphreys and Professor Brian Ford as this year's plenary speakers. Professor Humphreys will discuss how electron microscopy and atom probe tomography can save the world; by helping solve some of the world's energy problems and how they can also enable commercial exploitation of materials. His research interests include all aspects of electron microscopy and analysis, semiconductors (particularly gallium nitride), ultra-high temperature aerospace materials and superconductors. His work has ranged from defect image interpretation via electron diffraction theory to developing new electron microscope techniques. During his long and fruitful career, Prof. Humphreys received several international awards in recognition of his accomplishments, including the MSA Distinguished Scientist Award. He is a long-standing member of the Microscopy Society of America and was inducted as an MSA Fellow in 2009.

Our second plenary speaker is Prof. Brian Ford, an independent research biologist, author, and lecturer who regularly publishes on scientific issues for the general public. He has also been a television personality for more than 40 years. One of his bestknown discoveries was of the original specimens of Antony van Leeuwenhoek, which were well preserved within the collections of the Royal Society of London since the seventeenth century. Prof. Ford's fabulous lecture will be "Images from the earliest microscopes ever made". A Fellow and Member of Court at Cardiff University, Brian is a former Fellow at the Open University, Visiting Professor at the University of Leicester and a Member of the Senior Combination Room at Gonville and Caius College, Cambridge University, where he is currently based.

This year we have two named symposium to honor the life and work of Oliver Wells and Gérard Simon. Oliver C. Wells, who was a champion of all things related to the SEM, was Sir Charles Oatley's second PhD student at Cambridge University to work on the SEM (after Dennis McMullan) and is considered one of the founding fathers of the field. He was a particularly appreciated researcher and analyst who was willing to try something new or different even when all the experts of the day had already dismissed the idea. He was a tinkerer and had a passion for electron detectors. He had great respect for the analyst who was knowledgeable about the SEM and could obtain a plethora of information about a sample by varying all the controllable microscope parameters. He enjoyed meeting to discuss the SEM, always encouraged people to publish their work, and strove to give credit to individuals who were overlooked for significant work. His pioneering work and life will be celebrated in a memorial symposium bearing his name.

To honor Dr. Wells', his memorial session solicited papers on a wide range of topics central to his legacy: "low loss" electron imaging, energy filtered imaging, very high energy imaging, the origin of secondary electrons, new electron detectors, novel uses for established detectors, reducing sample charging in the SEM, and varying SEM analysis conditions to show different information about a sample. Since Dr. Wells was one of the "fathers" of the SEM, the session is also intended to showcase the evolution of the SEM and show how the SEM has contributed to society as a whole. Dr. Wells was also the grandson of H.G. Wells.

Our other memorial session honours Professor Gérard T. Simon who made many contributions to the development of microscopy in Canada. Born in Switzerland in 1931, Gerard T. Simon began a successful career as a professor of medicine at the University of Geneva where he created the first electron microscopy laboratory in the Department of Pathology. In 1967, he immigrated to Canada with his family where he became director of the Department of Electron Microscopy of the Banting Institute in Toronto.

The career of Gerard T. Simon led him to take over the electron microscopy laboratory of the Faculty of Health Sciences at McMaster University in Hamilton. In recognition of the exceptional accomplishment of Professor Simon in the Microscopical Society of Canada, a merit scientific award named after him is given annually to students in the fields of biological, physical and material sciences. When he retired in 1996, the Honourable Jean Chrétien, Prime Minister of Canada presented him an award in recognition of his professional achievement.

This year's M\&M promises to be one of the most exciting meetings ever. The Executive Program Committee and the Symposia Organizers have done a wonderful job planning the 2014 meeting. Each year we enhance and strengthen the Societies that come together to share and collaborate on scientific knowledge.

It is time for us to join together and participate in M\&M 2014 as Mark Twain wrote of the city of Hartford in 1868, "Of all the beautiful towns it has been my fortune to see this is the chief." The 2014 M\&M meeting promises to be the chief meeting of the year. The Executive Program Committee welcomes you to a celebration of microscopy and microanalysis in the city of Hartford, CT on Aug $3^{\text {rd }}-$ Aug $7^{\text {th }} 2014$. 


\section{Executive Program Committee}

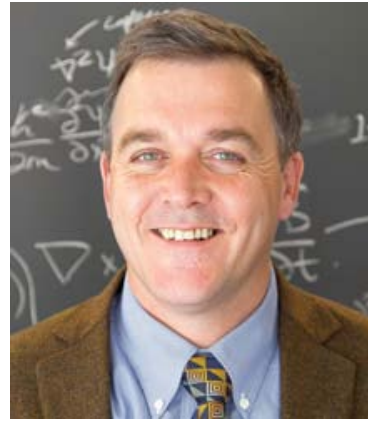

David Bell

Program Committee Chair

Harvard University

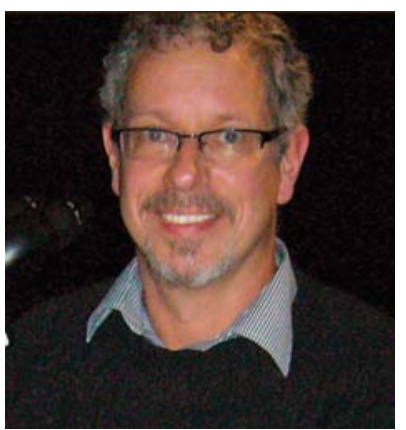

Mark Sanders

Program Vice Chair

University of Minnesota

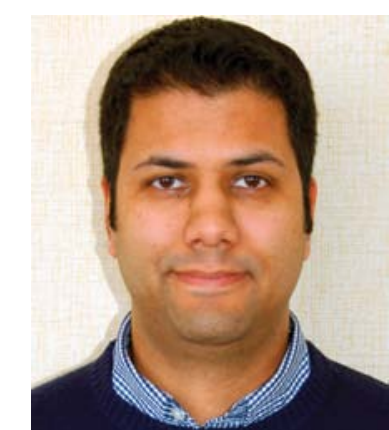

Yoosuf Picard

MAS Co-Chair

Carnegie Mellon University

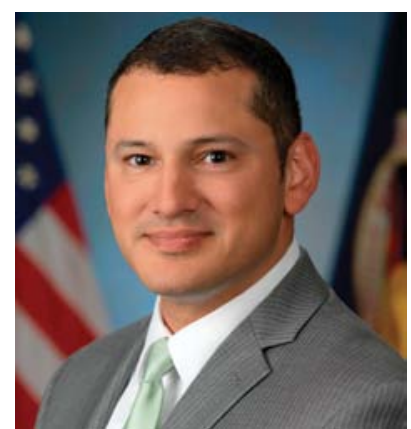

James Martinez

IMS Co-Chair

National Aeronautics and

Space Administration

\section{Anja Geitmann}

MSC Co-Chair

University of Montreal

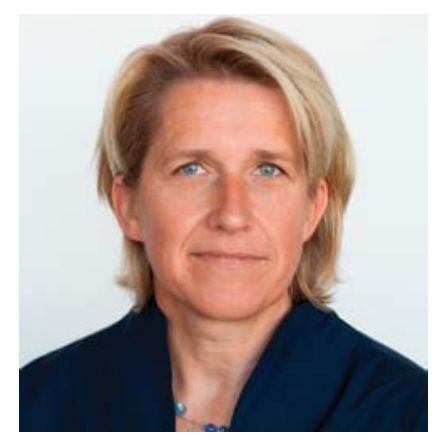

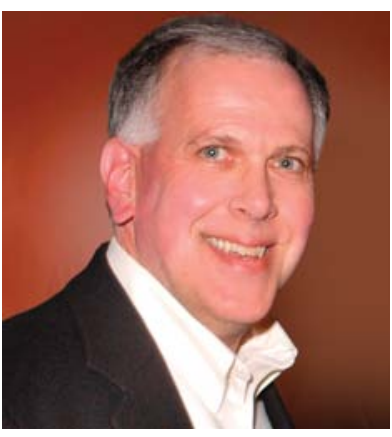

\section{Edward Vicenzi}

IUMAS Co-Chair

Smithsonian Institution 


\section{Committee Members and Session Chairs}

\author{
L. Anderson Johns Hopkins University \\ N. Antoniou Harvard University \\ R. Arenal Universidad de Zaragoza \\ J. Armstrong Carnegie Institution for Science \\ M. Baram McMaster University \\ David Becker Lee Kong Chian School of Medicine, Singapore \\ L. Bertrand Synchrotron SOLEIL \\ G. Botton McMaster University \\ N.D. Browning Pacific Northwest National Laboratory \\ Alyssa Calabro Bergen County Academies \\ P. Carpenter Washington University in St. Louis \\ J. Chandler Colorado School of Mines \\ J.A. Chaney The Aerospace Corporation \\ P.-M. Charest Université Laval \\ W. J. Christian Albrechts University \\ M. Chi Oak Ridge National Laboratory \\ J. Ciston Lawrence Berkeley National Laboratory \\ P.L. Clode University of Western Australia \\ L. Cohen-Gould Cornell University \\ D. Cooper French Alternative Energies and Atomic Energy \\ Commission \\ J. M. Davis National Institute of Standards and Technology \\ D.P. Dennies Exponent Inc. \\ A.C. Dohnalkova Pacific Northwest National Laboratory \\ O. Dugne French Alternative Energies and Atomic Energy \\ Commission \\ G. Dunny University of Minnesota \\ R. Erni EMPA \\ P. da Fonseca Georgia Institute of Technology \\ Z. Gainsforth University of California at Berkeley \\ L.A. Giannuzzi L.A. Giannuzzi and Associates \\ L.M. Gignac IBM T. J. Watson Research Center \\ C.J. Gilpin Purdue University \\ M. Goheen Indiana University \\ B.P. Gorman Colorado School of Mines \\ B.J. Griffin University of Western Australia \\ M. Haider CEOS Gmbh \\ F. Hogue Hogue Metallography \\ A.P. Hitchcock McMaster University \\ E. Humphrey University of Victoria \\ J.-C. Idrobo Oak Ridge National Laboratory \\ M. Jercinovic University of Massachusetts Amherst \\ J. Jerome Vanderbilt University \\ D. C. Joy University of Tennessee \\ M. Kim University of Texas at Dallas \\ A.I. Kirkland University of Oxford \\ R.F. Klie University of Illinois at Chicago \\ A.L. Koh Stanford University \\ P. G. Kotula Sandia National Laboratories \\ P. Kysar University of California, Davis \\ J. Lacoste MIA Cellavie \\ T. LaGrange Lawrence Livermore National Laboratory \\ R.D. Leapman National Institutes of Health \\ H. Lichte Technishe Universitat Dresden \\ P. Longo Gatan Inc. \\ F. Macaluso Albert Einstein College of Medicine \\ C.M. MacRae CSIRO-Minerals \\ M.B. Matthews Atomic Weapons Establishment UK
}

\author{
J.E. Martinez NASA Johnson Space Center \\ M. Marko Wadsworth Center \\ M.R. McCartney Arizona State University \\ S. McKernan 3M Corporation \\ D.L. Medlin Sandia National Laboratories
}

F. Meisenkothen National Institute of Standards and Technology

C. Miller Indiana University

S.E. Miller Duke University

F. Mücklich Saarland University

D.A. Muller Cornell University

P.D. Nellist University of Oxford

A.L. Olins University of New England

D.E. Olins University of New England

E. Olsson Chalmers University

N. Osakabe Hitachi Ltd

R.J. Parrington IMR Test Labs

D. Perovic University of Toronto

P. Phillips University of Illinois at Chicago

Y.N. Picard Carnegie Mellon University

P. Poeml EC-JRC Institute for Transuranium Elements

Craig Queenan Bergen County Technical Schools

M. Radermacher University of Vermont

Adam Robinson University of Cambridge

I. Rouiller McGill University

J.M. Rodenburg University of Sheffield

T. Ruiz University of Vermont

M.A. Sanders University of Minnesota

P. Santi University of Minnesota

I. Schmidt-Krey Georgia Institute of Technology

T. Schwarz Max-Planck-Insitut für Eisenforschung GmbH

K. Scott National Institute of Standards and Technology

V.S. Smentkowski General Electric

D. Shindo Tohoku University

D.J. Smith Arizona State University

S. Stagg Florida State University

M.A. Stevens-Kalceff University of New South Wales

T. Stroh McGill University

R.M. Stroud U.S. Naval Research Laboratory

C. $\mathrm{Su}$ Bruker-Nano

S.K. Sundaram Alfred University

K. Suenaga National Institute of Advanced Industrial

H. Takahashi JEOL Inc

E. Telfeyan U.S. Environmental Protection Agency

M. Varela del Arco Oak Ridge National Laboratory

E.P. Vicenzi Smithsonian Institution

J. Walmsley SINTEF

M. Walton Northwestern University

F. Wang Brookhaven National Laboratory

S.A. Wight National Institute of Standards and Technology

E.R. Wright Emory University

K.E. Wright Idaho National Laboratory

R. Wuhrer University of Western Sydney

H. Young University of Alberta

S. Zaefferer Max-Planck-Institut für Eisenforschung $\mathrm{GmbH}$

H. Zheng Lawerence Berkeley National Laboratory

Y. Zhu Brookhaven National Laboratory 